\title{
LA PARTICIPACIÓN DE LOS UNIVERSITARIOS DE CÓRDOBAEN LA FORMACIÓN DE LA NACIÓN 1810-1853
}

\author{
María Cristina Vera de Flachs 1 \\ Universidad de Córdoba-CONICET, Córdoba-Argentina \\ Grupo de investigación HISULA \\ vera@onenet.com.ar
}

Recepción: 28/04/2010

Evaluación: 09/06/2010

Aceptación: 18/06/2010

Artículo de Reflexión

\section{RESUMEN}

En la primera mitad del siglo XIX la Universidad Nacional de Córdoba de la República Argentina era un centro de estudios de reducida estructura pero con un enorme prestigio ganado a través de su historia. Ella sería protagonista -a través de sus ex alumnos- de la conformación de la Nación. En este artículo se tratará de analizar la participación de algunos de los universitarios desde el proceso de la independencia hasta que se sanciona la constitución nacional y la Universidad pasa a depender de la Nación.

Palabras clave: Universitarios, Córdoba, Siglo XIX, Formación de la Nación.

\footnotetext{
1 Doctora en Historia, Licenciada en Historia por la facultad de filosofia y humanidades, Profesora Titular de Historia Social Contemporánea. Facultad de Derecho y Ciencias Sociales. Universidad Nacional de Córdoba, Investigadora Principal del Consejo Nacional de Investigaciones Científicas y Tecnológicas. [CONICET]. Integrante del grupo de investigación Historia y Prospectiva de la Universidad Latinoamericana HISULA.
} 


\title{
THE PARTICIPATION OF THE UNIVERSITY PROFESSORS OF CORDOBA IN THE BUILDING OF THE NATION 1810-1853
}

\author{
María Cristina Vera de Flachs \\ Universidad de Córdoba-CONICET, Córdoba - Argentina \\ HISULA Research Group \\ vera@onenet.com.ar
}

\begin{abstract}
At the middle of the XIX Century, The National University of Cordoba, in Argentina, was a studies focus of small sized structure but it had a enormous prestige earned through its history. This institution there will be protagonist through its former students, and for the generation of the argentine Nation State. This paper will be devoted to the scrutiny of Cordoba University since the independence process, during this highly period, while the nation was struggling to reach its organization and get a Constitution. As well as, this paper shows moment when the university becomes "national".
\end{abstract}

Key words: Cordoba, XIX Century, Students. 


\section{INTRODUCCIÓN}

La Universidad de Córdoba ubicada en el centro de la República Argentina era, a fines del siglo XVIII, un centro intelectual de reducida estructura pero con un prestigio ganado a través de su historia. Un conjunto de circunstancias múltiples y complejas se entrelazaron para que ella, a través de la actividad desplegada por muchos de sus ex alumnos -juristas o filósofos- que ejercieron cargos de importancia en la sociedad colonial y en la etapa independentista, participara de lleno en la conformación de la Nación.

El objetivo de esta investigación es demostrar que muchos de los hombres que pasaron por sus aulas participaron activamente en la política nacional y local desde el mismo momento que el virreinato del Río de la Plata se independiza de España hasta la sanción de la constitución nacional en 1853. El conjunto de personajes seleccionados para cada una de las etapas históricas estudiadas fue significativo, aunque no fueron los únicos. Con su bagaje intelectual en filosofía, humanidades, ciencia política y ciencia pura sus egresados detentaron a lo largo de su vida distintas posiciones de poder, contribuyendo con sus ideas y compromiso a la organización nacional.

\section{Los Franciscanos al frente de la Universidad}

Desde su fundación y hasta la sanción de la Real Pragmática de Carlos III de julio de 1767 que ordenaba el extrañamiento de los religiosos de la Compañía de Jesús de todos los dominios de España, Indias e Islas Filipinas y demás adyacentes, la Universidad de Córdoba estuvo desde su fundación en poder de dicha Orden. En esa lapso la enseñanza, teológica y clerical, impartió los conocimientos de su tiempo y tuvo como tantas casas de estudios americanas y españolas épocas de esplendor y decadencia. Después de la expulsión de los jesuitas, los Franciscanos quedaron al frente de la misma, aunque desde el comienzo su accionar fue resistido por los defensores de aquellos y por el clero secular que se creía con derecho a detentar el control de la institución. Obviamente esto provocó altercados y enfrentamientos entre las distintas facciones que pujaron dentro y fuera de los ámbitos universitarios.

Los continuos debates políticos y académicos, mostraron claramente las posiciones existentes en la casa de estudios encarnadas por los antiguos y por los modernos, es decir por los partidarios de una universidad concebida al servicio de la Iglesia y, otra, encaminada a romper con antiguas ataduras con el fin de abrir las aulas a las nuevas ideas. Por eso fue común que, en ese tiempo, se 
criticaran las obras de la Ilustración y que algunos de sus representantes que estaban contra el regalismo a ultranza fuesen tildados de ateos, libertinos y materialistas. Valga a modo de ejemplo el caso del monserratense Antonio Esquerrenea, compañero de estudios de dos futuros miembros de la revolución de Mayo, Juan José Castelli y Saturnino Rodríguez Peña, que fuera reprendido en 1785 por el rector del Colegio Monserrat por ser adicto a "doctrinas nuevas". Lo que lo llevó a exclamar: "Dios lo libre de que le caigan en sus manos libros de los Países Bajos, o del Norte, y también los de algunos libertinos franceses." ${ }^{2}$

Evidentemente los textos de los autores ilustrados habían llegado a la Universidad y circulaban "entre gallos y medianoche", como manifestara otro ex alumno, Juan Ignacio Gorriti. ${ }^{3}$ Durante el lapso que los estudios universitarios estuvieron bajo la directriz de los franciscanos se siguió el plan reformista de la corona con las licencias propias que imponía la distancia a la metrópoli aunque ejerciendo un control estricto sobre los autores y doctrinas contrarias a la monarquía. Los profesores de esta etapa preferían la experiencia a la razón, principio de la Ilustración y donde esa renovación fue más evidente fue en los estudios de Física y Teología. Sin embargo, otros cambios tardaron en concretarse por las dificultades financieras del período que coadyuvaron para impedir la puesta en marcha de reformas importantes y por el tiempo que insumieron los pleitos entre los partidarios de los jesuitas y los seráficos, lo que terminó afectando la educación, la relación entre educandos y profesores y envolviendo en el conflicto a la sociedad toda. Dentro del grupo projesuitas se congregaron los hermanos Funes, los Allende, Antonio Savid, los Pérez Bulnes y otros que ya desde la clerecía, el cabildo o los negocios acabaron conformando un bloque sólido. De todos modos lo que nos interesa destacar es que, de una u otra forma, los ilustrados rioplatenses, pertenecientes a un mismo estrato social, poseían un aceptable nivel de instrucción lo que les posibilitó tomar conocimiento de lo que se discutía en Europa. Entre los antijesuitas podemos mencionar a los hermanos Victorino y Juan Justo Rodríguez, cuyo padre José de origen gallego fue un sólido comerciante que además actuó por más de veinte años como síndico de la universidad. Al coronel Santiago Alexo de Allende cuñado de José Javier Díaz, Benito Fragueiro, los frailes Pedro Sulivan

2 VERA DE FLACHS, María Cristina. (1999): Finanzas, saberes y vida cotidiana en el Colegio Monserrat. Del Antiguo al Nuevo Régimen, Córdoba, pp. 105. ARCHIVO HISTORICO DEL COLEGIO MONSERRAT, Libro Privado en que se apunta el ingreso $y$ salida de los colegiales, años 1772-1810, fs. 26.

3 Gorriti era hijo de un terrateniente de la provincia de Jujuy y estuvo comprometido desde el comienzo con la Revolución de Mayo, al punto de ser diputado por su provincia en la Junta Grande. En 1829 fue electo gobernador de su provincia, cargo que desempeñó hasta 1831. Al año siguiente, se expatrió voluntariamente á Bolivia en donde falleció en 1842 rodeado de la estima y consideraciones debidas á su talento, méritos y servicios. Allí escribió el libro titulado: «Reflexiones sobre las causas morales de las convulsiones interiores de los nuevos Estados Americanos". 
y Pedro Luis Pacheco y Juan Luís Aguirre un ex profesor de la Universidad que mantuvo pujas con el Deán Funes. ${ }^{4} \mathrm{El}$ análisis de las trayectorias de algunos de estos personajes nos permitirá analizar sus recorridos y su participación en los distintos momentos de la historia local y nacional.

Entretanto, ¿cuál era la situación de la Universidad al comienzo del nuevo siglo? Por real cédula del 1 de diciembre de 1800 Carlos IV dispuso se "erija y funde de nuevo en Córdoba una Universidad Mayor, con los privilegios y prerrogativas que gozaban las de esta clase en España e Indias, a la que le dio el título de Real Universidad de San Carlos y de Nuestra Señora de Monserrat, aunque el traspaso al clero secular se produjo recién en 1807. Estas disposiciones le permitieron al Deán Gregorio Funes asumir el rectorado y a partir de entonces su figura estará indisolublemente unida a la vida universitaria. Con su nombramiento se consiguió poner un poco de calma en la ciudad y entonces él pudo poner en marcha algunas de sus ideas sobre educación superior.

\section{Los universitarios en épocas de la Revolución}

Es decir de la etapa pre revolucionaria la figura más representativa es sin duda la del Deán Funes, del que nos hemos ocupado en otras oportunidades. Formado por los jesuitas fue, junto a su hermano Ambrosio, un férreo defensor de la Orden durante la etapa que los franciscanos estuvieron al frente de la Universidad al punto de señalar que la aurora de las luces habría empezado a rayar en los últimos años que los jesuitas regentearon la Universidad. ${ }^{5}$ Completó su formación con una estancia en la Universidad de Alcalá de Henares, lo que le permitió tomar contacto con las concepciones jusnaturalistas, especialmente con la escuela holandesa y alemana que habían introducido la ciencia jurídica de moda: el Derecho Natural y de Gentes a través de las obras de los grandes internacionalistas alemanes como Puffendorf, Grocio, Thomasio o Wolf los que fueron conocidas a través de Vattel, Burlamaqui o Felici. Después del estallido de la Revolución Francesa algunas de estas obras fueron prohibidas pero, sin duda, las lecturas previas de los textos de Juan Teófilo Heineccio, Elementos de Derecho Natural y de Gentes; el Tratado de Derecho Natural y de Gentes de Samuel Puffendorf y el Derecho de la Guerra y de la Paz de Hugo Grocio, le brindaron al Deán los argumentos teóricos para justificar políticamente la Revolución de Mayo. ${ }^{6}$ Otros autores como

4 AYROLO, Valentina. (2007): Funcionarios de Dios y de la república. Clero y política en la experiencia de las autonomías provinciales, Buenos Aires, Editorial Biblos, pp. 180 y ss.

5 FUNES, Gregorio. Ensayo de Historia Civil, Tomo 3, p. 182.

6 VERA DE FLACHS, María Cristina. (1999): "Gregorio Funes: un criollo ilustrado y la reforma del plan de estudios de la Universidad de Córdoba”, en Científicos Criollos e Ilustración, Editorial Doce Calles, Madrid, pp. 123 y ss. 
Condillac -citado en varios de sus escritos- y la Enciclopedia, colección que conservaría hasta su muerte, le viabilizaron el conocimiento de las concepciones demoliberales. ${ }^{7}$ También el Deán se reconoció discípulo de Gaspar Melchor de Jovellanos y admirador de Feijóo lo que explica su preocupación por la educación y la difusión del conocimiento útil y funcional. La enumeración de estos autores es demostrativa de los conocimientos que poseía la generación que actuará en la época independentista.

Como buen reformista ilustrado Funes buscó compatibilizar esas ideas con la fe católica. A su vez los pensadores antes mencionados le proporcionaron una nueva concepción política, la que lo llevaría a convertirse en uno de los defensores de la segregación del virreinato del Río de la Plata de España y liderar parte de los conflictos políticos de la primera década revolucionaria. Es que muchos de los temas acunados por aquellos fueron modificando su pensamiento y así fue preocupándose por la urgencia de repensar la constitución de la sociedad política, por los derechos naturales del hombre, los fines y límites del poder público y por el derecho de los pueblos a la resistencia y a la rebelión. Por ejemplo, en 1790 cuando la muerte de Carlos III, Funes pronunció la Oración fúnebre, donde aparecieron premonitoriamente algunas ideas políticas básicas que evidencia influencia de Jovellanos y al hacer el elogio del monarca expuso su teoría del pactum societatis, que está dentro de la línea de los pensadores ilustrados. Entonces exclamó: "El funesto Peripato hacía sus últimos esfuerzos para sostenerse en España, donde se hallaba como encerrado huyendo de las sublimes meditaciones de los Descartes, Galileis, Newtones, Lokes y Leibnitz, pero ya se conocía que ya se hallaba en la vejez, que sus fuerzas iban a menos y que apoyados al buen gusto y la razón sólo los sólidos fundamentos del trono, era inevitable su ruina."

En 1805 y en ocasión de las exequias del Obispo de Tucumán tuvo similares expresiones, sólo que esta vez repitió frases de Massillon y, en 1807, cuando escribió sobre el rechazo de los invasores ingleses, utilizó la Oraison funèbre de Bossuet.

Lo aseverado demuestra que antes de la independencia hubo universitarios que fueron mirando con recelo a la madre patria y ellos fueron los que participaron

\footnotetext{
7 Y ello se prueba pues en varios de sus escritos dio testimonio de la formación adquirida en España y América. I.E.A. Documento $N^{\circ}$ 6.399. PEÑA, Roberto, "Los derechos naturales del hombre en la ideología del siglo XVIII Rioplatense", en Academia Nacional de Derecho y Ciencias Sociales de Córdoba, Instituto del Derecho y de las Ideas Políticas, Cuadernos de Historia $N^{o} 2$, 1992, p. 29.

8 Borrador del original de la oración fúnebre por las exequias de Carlos III pronunció en esta ciudad de Córdoba el Deán Don Gregorio Funes, año 1790, Imprenta de Niños Expósitos, Colección Pablo Cabrera.
} 
del movimiento independentista de Mayo de 1810. Obviamente la respuesta no fue homogénea, hubo revolucionarios pero también contrarrevolucionarios, no obstante uno de los elementos que aglutinó a los ambos grupos fue la Iglesia que actuó como mediadora y fuente de legitimidad y la pertenencia a un grupo o red relacionados por un entramado social, económico y político.

La revolución de Mayo obligó a las elites del interior a debatir en los recintos capitulares el curso de los acontecimientos para ver cuál era el camino a seguir. La noticia del movimiento revolucionario fue reportada a Córdoba por un ex alumno del Colegio Monserrat, José Melchor Lavín, quien arribó a la ciudad del mismo nombre el 30 de ese mes portando las instrucciones reservadas de la Junta. El entró en contacto con las autoridades locales a través del Deán Funes, de quien había sido alumno. Al día siguiente, el gobernador intendente reunió a los máximos dirigentes para decidir si aceptaban o rechazaban el nuevo órgano de gobierno. La revolución exigía una definición de la causa y en este aspecto las fuerzas políticas de Córdoba se dividieron y la mayoría acordó no prestar obediencia al nuevo gobierno.

Entretanto la facción de los Funes emprendió, a través de pasquines y una gaceta manuscrita denominada El Duende Americano, una activa propaganda revolucionaria. Los más entusiastas defensores de esa postura eran los doctores y estudiantes de la universidad.

Por su parte, los contrarrevolucionarios contaban con un plan y fuerzas locales de apoyo a los que se sumarían los de las regiones cuyanas y de otras partes del Alto Perú y Paraguay. Pero la Junta provisoria establecida en Buenos Aires debía desmantelar este foco contrarrevolucionario cordobés si quería evitar la división de los pueblos del interior. Para ello no sólo debía perseguirlos sino que debía producir una sanción ejemplar que "escarmiente y aterre a los malvados". Las órdenes eran precisas: decapitar y desarmar la cúpula disidente, reclutar fondos para la campaña al Alto Perú y asegurar obediencia. Y esto es lo que ocurre. ${ }^{9}$

Entretanto el movimiento de mayo encontró a la Universidad con autoridades nuevas. En enero de 1810 asumió como rector el obispo de Córdoba Rodrigo

\footnotetext{
9 En efecto, una expedición al mando del coronel Francisco Ortiz de Ocampo persigue y atrapa al gobernador Gutiérrez de la Concha, al dr. Victorino Rodríguez, el coronel Allende, el oficial real don Joaquín Moreno, Santiago Liniers, el canónigo Tadeo Llanos y el Obispo Orellana quienes emprenden viaje a Buenos Aires, con excepción de Llanos que regresó a Córdoba. Pero la Junta manda una partida para impedir que lleguen a esa ciudad y se ejecute la sentencia. Los cabecillas fueron ejecutados, excepto el obispo que salvó su vida por mediación del deán Funes. Obviamente la noticia de estos fusilamientos causó gran conmoción en la ciudad e inclinó la balanza a favor de los revolucionarios.
} 
Antonio de Orellana y como vicerrector el Deán Funes, cargo que le correspondía después de terminar su rectorado de acuerdo a las Constituciones de Lima. Como consiliarios fueron elegidos Miguel Calixto del Corro, Pedro Ignacio de Castro Barros y José Gregorio Baigorrí. Este pequeño grupo de hombres fue protagonista destacado en la academia y en la política en la primera década revolucionaria y junto con otros universitarios conformaron una red que tuvo protagonismo en los años de la formación de la Nación. Usamos el término grupo o red como sinónimos en tanto expresan la idea de un conjunto de personas unidas a través de lazos definidos y que participan de proyectos comunes. La jurisprudencia y la teología fueron las carreras que les proporcionaron las herramientas necesarias para su inserción política aunque hay que destacar que, para entonces, eran muchos los teólogos que habían demostrado mayor pasión por la política que por los estudios religiosos.

Sin embargo contra lo que se podría suponer en las reuniones del claustro universitario no hubo en este momento político afirmaciones significativas. ¿Influyó el hecho que entre los hombres que actuaban en él hubo algunos que tenían miedo de expresar sus ideas abiertamente todavía? La realidad es que, por lo general, en la primera mitad del XIX en las reuniones de claustro hay escasas referencias a la situación política imperante en el país.

De todos modos muchos de los egresados de la Universidad de Córdoba, por otra parte única casa de estudios superiores existente en lo que será el territorio argentino, dominaron la escena política de entonces formando parte de los primeros gobiernos patrios. Ellos buscaran corregir el caos producido por la guerra civil y efectuar el cambio de las estructuras coloniales.

Es que en Argentina, como en cada uno de los Estados americanos que alcanzó su independencia en la segunda década del XIX, pronto se sintió la necesidad de ordenar política y jurídicamente el país. La falta de experiencia y el escaso conocimiento del pueblo en materia de Estado, llevó a teólogos y abogados, tal vez los hombres mejor preparados de cada jurisdicción, a ejercer un importante papel en este aspecto, lo que se vio reflejado en la participación que tuvieron en la redacción de los Reglamentos, Constituciones y Leyes promulgadas entones.

Gregorio Funes con su pensamiento y actuación contribuyó en esa primera década en el devenir revolucionario. Su adhesión al movimiento de mayo está registrada en un documento titulado Parecer del Deán de la Iglesia de Córdoba Dr. Gregorio Funes, referente al nuevo Gobierno establecido en la Capital del Virreynato y dado en la Junta celebrada con este motivo en 
casa del gobernador de esta provincia que circuló en Córdoba y luego publicada en La Gazeta de Buenos Aires, se convirtió en una especie de catecismo político que se leía desde los púlpitos con el fin de sensibilizar a los pueblos con el nuevo sistema. ${ }^{10}$ Él, junto a Pedro Ignacio de Castro Barros y José Ignacio Gorriti, conformaron lo que se conoció como "el triunvirato de la revolución", gravitando con sus ideas profundamente en la vida del Río de la Plata. Los tres eran hijos de la Ilustración católica, formados en la universidad colonial adherían a los principios de la filosofía moderna y a las teorías económicas en boga (neomercantilismo, fisiocracia y liberalismo) más tarde devinieron en anticentralistas, defensores de la igualdad de las provincias y contrarios al aire de superioridad que solían ostentar los porteños. ${ }^{11}$

\section{La Declaración de la Independencia y los Universitarios}

Como señalamos el grupo primigenio de cordobeses que actuó en el primer momento de la revolución se fue enriqueciendo y ampliando con otros ex universitarios que, a su vez, mantenían lazos de amistad o parentesco entre ellos, los que se fortalecieron cuando se vincularon en los distintos proyectos que se implementaron en el país después de 1810 aunque no en todas las ocasiones expresaron idénticas posiciones políticas.

Es visible la participación de esta red en el Congreso convocado en Tucumán en 1816 con el fin de declarar la independencia de España. De 29 congresales que firmaron el acta respectiva, 14 pasaron por las aulas de la casa de Trejo. Ellos fueron los Doctores Manuel Antonio Acevedo, Pedro Aráoz, José Eusebio Columbres, Pedro Ignacio de Castro Barros, Miguel Calixto del Corro, Pedro León Gallo, José Ignacio Gorriti, José Ignacio Thames y los licenciados José Antonio Cabrera y Luís Jerónimo Salguero de Cabrera y Cabrera. Fray Cayetano Rodríguez, figura prominente de ese tiempo, no egresó de esta Universidad aunque permaneció en ella entre 1781 y 1790 dictando los cursos de Física, Metafísica y Lógica. ${ }^{12}$ El resto de los congresales había egresado de

\footnotetext{
${ }^{10}$ LA GAZETA, Martes 7 de agosto de 1810. Ver en "Escritos políticos de Deán Gregorio Funes. 1810-1811" en Estudios N ${ }^{\circ}$ 11-12, UNC, CEA, Córdoba, diciembre de 1999 , p. 125 y ss.

11 Se designa así a los habitantes del puerto de Buenos Aires.

12 Desde el comienzo Fray Rodríguez fue uno de los partidarios más fervientes de la revolución al punto que lanzó un manifiesto justificándola en virtud de las vejaciones sufridas en América. Siendo provincial expidió en 1812 una circular exhortando a sus súbditos a no perturbar el orden público. Participó de la Asamblea del año XIII siendo su redactor. Las cuestiones de derecho público eclesiástico le preocuparon sobremanera hasta su muerte ocurrida en 1823. Celina LERTORA MENDOZA, Fray Cayetano Rodríguez, Curso de Física. 1786-1792, Cuadernos de la Junta Provincial de Historia de Córdoba, 2003.
} 
las Universidades de Charcas y de Santiago de Chile, lo que reafirma nuestra tesis inicial que los egresados universitarios conformaron la elite de poder en América. ${ }^{13}$

Los cuatro diputados que representaron en ese congreso a Córdoba pertenecían al grupo social que detentaba el poder en Córdoba, ellos fueron: José Antonio Cabrera, Miguel Calixto del Corro, ${ }^{14}$ Jerónimo Salguero de Cabrera y Cabrera y Eduardo Pérez Bulnes. Los tres primeros, ex alumnos de la Universidad, marcaron con su presencia la resistencia federal de la provincia contra del centralismo porteño en oportunidad de discutir la proclamación de la independencia y la forma de gobierno que adoptaría la Nación. Debido a la defensa que realizaron al federalismo actuaron casi en soledad en las deliberaciones, contando sólo con el apoyo del diputado por Salta, don Mariano Boedo, y circunstancialmente con algún otro representante del interior. La postura adoptada, a veces, hizo que otros congresales los agraviaran tildándolos de anarquistas o los acusaran hasta de sustraer correspondencia oficial.

Otro personaje importante de ese Congreso, hijo de la Universidad de Córdoba, fue Pedro Ignacio de Castro Barros. Nacido en 1777 en un pueblo de la provincia de La Rioja se doctoró en teología en Córdoba donde obtuvo por oposición la cátedra de Filosofía y luego actuó como consiliario y rector. En 1813 regresó a su provincia natal siendo elegido para representarla en la Asamblea del año XIII y, en 1816, fue diputado en el Congreso de Tucumán, ocasión donde expuso sus ideas mostrando en sus afirmaciones profundidad, erudición y un acendrado sentimiento patriótico e independentista comparable a la defensa que ejercía de la Iglesia basada en los valores más puros del catolicismo. Al igual que fray Cayetano Rodríguez, justificó la guerra de la independencia y sostuvo que la dominación española era tiránica.

Su pensamiento en torno a la forma de gobierno que debía adoptar el país fue expuesto en la sesión del Congreso Constituyente del 31 de julio de 1816 donde defendió el sistema monárquico constitucional por ser el más favorable a la conservación y progreso de la religión católica, y el menos sujeto a los males

\footnotetext{
13 VERA DE FLACHS, María Cristina. (1987): "La Universidad como factor de ascenso a la elite de poder de la América Hispana: el caso de Córdoba", en Congreso Internacional de Historia de las Universidades Americanas y Españolas, Claustros y Estudiantes. Facultad de Derecho, Universidad de Valencia, España.

${ }^{14}$ Del Corro quien se doctoró en Teología en 1798. Participó en varias comisiones pacificadoras y fue rector de la Universidad de Córdoba en dos oportunidades, 1816 1817 y $1829-1831$.
} 
políticos que afectaban cotidianamente a otros. ${ }^{15}$ No fue el único que pensaba de esa manera, otros habían considerado que los vínculos con el monarca debían pactarse bajo nuevas condiciones acordes a los derechos del liberalismo ilustrado.

La relación entre la Iglesia y el Estado era un tema que debía definirse en estos años y las posiciones iban desde las ideas más ortodoxas hasta las más regalistas. Castro Barros, ferviente católico y defensor apasionado de la ortodoxia durante toda su vida enfrentó a toda corriente ideológica que se opusiese a la Iglesia, ya fuese el galicanismo, el jansenismo o el regalismo. Nunca se cansó de proclamar sus principios frente a quienes pretendían someter a la Iglesia al brazo secular, planteando constantemente que el poder espiritual como el temporal, eran diferentes en su origen y fines. Por lo tanto reclamó el respeto a la autarquía de cada institución, lo que en definitiva conllevaba al respeto del poder temporal de la Iglesia por parte de la autoridad política. Sobre este punto hizo referencia en su celebre Oración Patriótica de 1815, cuando en Tucumán señaló: "Tenemos sobre la tierra dos madres muy comunes benéficas, a cuyos pechos, como compuestos de cuerpo y alma, mamamos la leche de los bienes temporales y espirituales". De esas madres comunes dependían los bienes temporales y espirituales y ellos eran la Patria y la Iglesia, por lo que ambas debían estar unidas. De tal manera que piensa que no era posible el Estado sin la religión católica pues para él el origen último del poder es Dios, como causa de todo orden natural.

Castro Barros también supo hacerse notar en octubre de 1817 cuando el Congreso trató el artículo octavo del decreto de libertad de imprenta que establecía que las obras que tratasen de religión no se podían imprimir sin censura previa del Eclesiástico. En caso de reclamo la obra sería analizada nuevamente por el mismo diocesano, aunque asociado con cuatro miembros de la Junta Protectora y la pluralidad de votos haría la sentencia irrevocable. ${ }^{16}$ Poco después, el 3 de diciembre, el diputado Zavaleta planteó la necesidad de enmendar el citado artículo de modo que las obras que tratasen de religión no podrían imprimirse sin previa censura del prelado diocesano y si la parte interesada reclamaba debía hacerlo ante los jueces y en el modo de que disponían las leyes

\footnotetext{
${ }^{15}$ Se ocuparon de este personaje. Américo TONDA, Castro Barros. Sus ideas, Academia del Plata, Bs. As 1961. MOLINA, José. (2001): El doctor don Pedro Ignacio de Castro Barros, Revista Nacional, VII, 1888, Buenos Aires. SILLAU PEREZ, Antonio. (2001): "Contenido y características del pensamiento político de Ignacio de Castro Barros en la primera década revolucionaria" en Revista de la Junta Provincial de Historia, No 18, Córdoba, pp. 215.

${ }^{16}$ Asambleas Constituyentes Argentinas, seleccionadas, coordinadas y anotadas por Emilio Ravignani, Buenos Aires, 1937, p. 263 y 340.
} 
de la Iglesia, reclamo aceptado por Castro Barros en tanto pensaba que el juicio sobre una obra de religión le concernía a la Iglesia y que no era cuestión del Estado. Su apoyo a esta medida junto a su proposición, aceptada luego por el Congreso Constituyente, que se tomara alguna providencia a efectos de precaver los males que se originaban de la venta y uso público de las obras de los pensadores que atacaban o ridiculizaban a la religión pusieron de manifiesto su férrea defensa del tema y la necesidad de conservar los valores tradicionales heredados.

Castro Barros cooperó activamente a lo largo de su vida de otros proyectos constitucionales. Por ejemplo, en 1821 fue elegido para participar en un Congreso constituyente que se celebraría en la ciudad de Córdoba con el fin de sancionar una constitución. Fracasado ese intento, la Universidad le confió el cargo de rector y cancelario desde 1825 a 1829 , período en el que dictó clases en el Monserrat y representó a la ciudad de Córdoba en la Legislatura. Durante el gobierno del general José María Paz en Córdoba fue vicario capitular, pero a la caída de éste fue apresado junto con cien vecinos y enviado a una cárcel a Santa Fe. En 1841 enfrentó al régimen rosista y como tantos otros debió exiliarse en Chile. En Santiago formó parte del claustro docente de la Universidad de San Felipe, dictando clases de Filosofía e Historia eclesiástica, falleció en esa ciudad en 1849.

\section{La suerte de la Universidad y un nuevo ciclo político}

Entre 1810 y 1820 el país logró declarar la independencia en 1816 y sacar la guerra fuera de sus fronteras pero la organización institucional se pospuso hasta 1853. En efecto, los intentos realizados para organizar el Estado en la primera década revolucionaria fracasaron y demostraron que la situación política se complicaría en los años por venir.

El orden directorial era resistido en Córdoba por dos corrientes de muy distinta extracción: la que dirigían los caudillos del litoral y la que obedecía a un movimiento federalista que nacía de la Universidad de Córdoba y que soñaba con una democracia institucional. ${ }^{17}$ En consecuencia, las pasiones políticas agitarán esta ciudad al tiempo que la montonera santafecina penetraba en su jurisdicción.

\footnotetext{
${ }^{17}$ PEÑA, Roberto. (1998): "El Doctor Manuel A. de Castro: gobernador de Córdoba, 1817-1820", en Cuadernos de Historia, Academia Nacional de Derecho y Ciencias Sociales, Córdoba, p. 45.
} 
En definitiva, el año 1819 concluía con la renuncia del gobernador de Córdoba, con la disolución del Congreso de Tucumán reunido en 1816, que había logrado declarar la independencia pero no sancionar una constitución definitiva para el país y con una gran sequía y manga de langostas que afectaban la economía provincial. Obviamente tales turbulencias afectaron la Nación que carecía de una autoridad central. Fue en esta etapa que las provincias consolidaron su propia autonomía hasta 1852. La descentralización política es en esencia el sistema de dominación imperante y esa fragmentación refleja la imposibilidad de conciliar intereses para emprender la formación del Estado. En este período desapareció el Cabildo, institución colonial que vuelve a mediados del siglo XIX con la instalación del Municipio. Por otra parte, la guerra de la independencia que tantos esfuerzos había costado se alejaba del suelo argentino pero se reanudaba la guerra civil, lo que produjo un estado de insurgencia permanente, obligando a los gobernantes a impartir órdenes de recolectar caballada, mulas y granos existentes, siendo las estancias de los opositores políticos las primeras en ser saqueadas, al tiempo que los hombres fuertes y jóvenes huían para no ser reclutados.

Entretanto, la Universidad sintió la necesidad debía realizar reformas acordes a los nuevos tiempos políticos. Coincidente con este propósito en 1818 el gobernador de Córdoba, Manuel Antonio de Castro, también ex alumno de la misma inició, el 23 de abril, una visita a la institución que culminó meses después con el arreglo de sus archivos, con la creación de la Biblioteca sobre la base de los despojos de la librería jesuítica y con un aumento significativo a las remuneraciones de los catedráticos. ${ }^{18}$ Sin embargo dejó en vigor el método de estudios existente hasta que el gobierno nacional lo uniformase en conformidad a las "luces de Europa". La realidad era que poco podía hacerse pues la pobreza de la institución y de la provincia era notoria y el plan de estudios elaborado por el Deán no se había podido poner en práctica en razón de esa situación económica. Esto llevó por esos días a Ambrosio Funes a señalar que los estudios estaban decaídos y dominados por maestros sin celo, ni educación, sujetos a parcialidades, situación que había sido comprobada por un viajero inglés de paso por Córdoba. ${ }^{19}$

Los sucesos políticos de marzo de 1820 trajeron como consecuencia que la Legislatura de Córdoba designara al general Juan Bautista Bustos como

\footnotetext{
18 Manuel Antonio Castro estudió en la Universidad de Córdoba aunque se doctoró en la de Charcas. Sin embargo su relación con la primera fue muy estrecha durante toda su trayectoria.

${ }^{19}$ Se refería a Alexander Caldcleugh quien, en 1825, publicó un libro de viajes donde dejó constancia de lo que aseveramos en el texto.
} 
gobernador en propiedad y que la provincia se constituyera como un Estado independiente y soberano. Se abría así un nuevo ciclo político. Obviamente la primera preocupación de éste sería organizar constitucionalmente el gobierno de la misma. Para tal fin recurrió a los clérigos doctores José Gregorio Baigorrí y José Norberto de Allende, ex alumnos de la Universidad, quienes el 10 de enero de 1821 presentaron el Reglamento Provisorio para el Régimen y Administración de la provincia, el que fue sancionado y promulgado a fines de ese mes con el fin de organizar el gobierno. El mismo ha sido considerado como una verdadera pieza constitucional, sin embargo él era elitista pues al señalar las condiciones que debían tener los representantes de la cámara estipuló que debían contar con veinticinco años de edad, un fondo de dos mil pesos propios y en caso de profesar "algún arte liberal" con título expedido por una Universidad.

El cambio de gobierno influyó directamente sobre la Universidad y su Colegio, instituciones que pasaron a depender exclusivamente de la órbita provincial. A partir de entonces y hasta la nacionalización de ambas instituciones los gobernadores de Córdoba ejercieron el derecho de patronato que antes había pertenecido a los virreyes y, luego, a las autoridades emanadas de la Revolución. Bustos, interesado en el progreso de la educación en la región, se preocupó por la Universidad y entre sus iniciativas más importantes destacamos el establecimiento de una imprenta pública, con la idea que ella pudiera editar textos para la enseñanza pues ese era el único camino que los ilustrados pensaban servía para propagar las luces, formar la opinión pública y consolidar la unidad de sentimiento que era la conservación del orden y la verdadera fuerza de los Estados. ${ }^{20} \mathrm{El} 15$ de noviembre de 1822, por decreto, el gobernador señaló que la imprenta solo tenía como única limitación no publicar nada que atacara a la religión del Estado y a las autoridades del país, que incitara a la sedición o a trastornar el orden público, que ofendiese el decoro de la decencia pública o desobedeciera las leyes, el honor, etc. En realidad, ella fue utilizada en los años siguientes para imprimir periódicos opositores y una gran profusión de panfletos hasta 1852 .

Luego encomendó al canónigo de la catedral Dr. José Dr. José Gregorio Baigorrì, de quien hicimos referencia para que realizara una visita oficial a la institución y redactara un nuevo plan de estudios. ${ }^{21} \mathrm{Al}$ iniciar su tarea, aquel elogió el plan de estudios de Deán Funes, sin embargo dado el tiempo transcurrido

\footnotetext{
20 Se ocuparon de este tema: Pablo CABRERA Monseñor. (1930): La segunda imprenta de la Universidad de Córdoba, Córdoba; U. BISCHOFF, Efraín. (1976): Las viejas imprentas de la Universidad, Córdoba, Universidad Nacional de Córdoba, Dirección General de Publicaciones.

21 Baigorrí nació en Córdoba el 12 de marzo de 1778. Se graduó en la Universidad como doctor en Teología y Cánones en 1802 y ejerció el cargo de rector de la misma. Falleció en esta ciudad el 9 de junio de 1838 antes de ser consagrado Obispo. Entre esas normas
} 
creía necesario realizar reformas y proveer a la Universidad de normas que carecía. En la Facultad de Teología unió el estudio de esta materia con el derecho canónico, por el cual a su término los cursantes podían optar al título de Dr. en Teología y en Derecho Canónico. Dispuso el 1 de marzo como inicio de clases y el 1 de noviembre su finalización. En los primeros quince días de este último mes habría solo una hora de conferencias a la mañana. A partir del día 18 se iniciaban los exámenes y una vez concluidos, los alumnos continuaban con clases a la mañana, excepto las de gramática, hasta vísperas de Navidad que era cuando cesaban las actividades y se entraba en vacaciones. Acorde a los tiempos políticos que se vivían reiteró que los días 25 de mayo y 9 de julio debían ser celebrados por todas las corporaciones del Colegio Monserrat y de la Universidad como días patrios.

Esta reforma fue aprobada por Bustos quien la envió al claustro para que ordenara ejecutarla a la mayor brevedad encargando al rector y a los que les sucedieran que contribuyeran a cumplir con ella. ${ }^{22}$ Baigorrí, por su parte, encargó a Juan Antonio de Sarachaga y a José María Bedoya la redacción de la nueva constitución por la que debía regirse de allí en adelante la Universidad ${ }^{23}$. Las luces de los comisionados y los conocimientos prácticos adquiridos en sus años de catedráticos le permitieron expedirse rápidamente. Concluida la visita, el claustro eligió las autoridades universitarias recayendo el rectorado en el Dr. Pedro Ignacio de Castro Barros.

Córdoba era a fines de la década del veinte la segunda región económica más importante de la zona del Plata sin embargo las luchas civiles habían obligado a sus hombres a desatender las faenas rurales, al tiempo que como señalamos para sufragar los gastos de la guerra civil, sus gobernantes recurrieron, en varias oportunidades, a los empréstitos forzosos. Obviamente esta situación incidió en la economía de la Universidad que con menos estudiantes entró en un colapso económico. Las entradas disminuyeron y los recursos no alcanzaban a cubrir las

\footnotetext{
Baigorrí insistió en el manejo del latín, sin descuidar el estudio de otros idiomas, aunque suprimió la enseñanza del francés hasta que los fondos se acrecentaran y permitieran erigir nuevamente la cátedra. Señaló la necesidad de fomentar el dibujo, la música, la poesía y las matemáticas, materia que él mismo enseñaba. Entre los textos recomendados figuraba la gramática castellana de Valdés y la latina del reverendo padre fray Diego de Mello y Meneses, corregida y aumentada por Luís Mato y Araujo, preceptor de latinidad en Madrid, que venía a reemplazar a la de Antonio de Nebrija.

${ }^{22}$ En retribución a la tarea emprendida en la Universidad Baigorrí recibió un sueldo mensual de 50 pesos entre el 23 de julio de 1822 y febrero de 1825. A.G.U.C., Libro 7, Documentos. 1823-1826, fs. 96 a 151 y 257 a 259. I.E.A., Documento No 12.791 .

23 Juan Antonio SARACHAGA. Ingresó a la Universidad de Córdoba y se recibió en 1804. Ardiente partidario de la Revolución de Mayo fue rector y vicerrector de la Universidad y reemplazó en la cátedra a Victorino Rodríguez. Fue encarcelado en la época de Rosas, recuperó su libertad. Luego fue apresado y fusilado en Buenos Aires el 2 de mayo de 1840. José María BEDOYA regenteaba la cátedra de matemática y física.
} 
dotaciones de cátedra, ello hará disminuir su prestigio respecto a épocas anteriores al tiempo que los gobernantes se arrogaron el poder de remover al rector y catedráticos a su antojo. Esta situación se mantuvo prácticamente igual hasta 1853 cuando la institución se transformó sobre otras bases. Obviamente ello coadyuvó para que en el período iniciado en 1820 y concluido en 1853 la Universidad contara con escasos 189 egresados en Filosofía, Teología y Derecho. En el cuadro que sigue observamos los de estas dos Facultades.

\section{EGRESADOS 1821-1852}

\begin{tabular}{|c|c|c|c|c|c|c|}
\hline & \multicolumn{3}{|c|}{ TEOLOGIA } & \multicolumn{3}{|c|}{ DERECHO } \\
\hline AÑO & ВАСН. & LIC. & DR. & ВАCH. & LIC. & DR. \\
\hline 1821 & & & & 1 & & \\
\hline 1822 & & & & 3 & 4 & \\
\hline 1823 & & & & 2 & & \\
\hline 1824 & & & & 3 & & \\
\hline 1825 & & & & & 2 & \\
\hline 1826 & & 1 & & & & \\
\hline 1827 & & 1 & 2 & & & \\
\hline 1828 & 4 & & & 4 & & 3 \\
\hline 1829 & & & & 1 & 1 & 1 \\
\hline 1830 & & 2 & 2 & 4 & 3 & 2 \\
\hline 1831 & & & & 2 & 1 & 1 \\
\hline 1832 & 3 & 3 & 3 & 4 & 1 & 1 \\
\hline 1833 & & & & & & \\
\hline 1834 & & & & 7 & 1 & 1 \\
\hline 1835 & & & & 2 & & \\
\hline 1836 & & & & 2 & 5 & 3 \\
\hline 1837 & & & & & & \\
\hline 1838 & & & & 2 & 1 & \\
\hline 1839 & & & & 4 & & \\
\hline 1840 & & & & & 1 & \\
\hline 1842 & & & & 4 & 1 & 1 \\
\hline 1843 & & & & 1 & 1 & 1 \\
\hline 1844 & 2 & 2 & 2 & 1 & 2 & 3 \\
\hline 1845 & & & & 4 & 1 & 1 \\
\hline 1846 & & & & 1 & 3 & \\
\hline 1847 & & & & 3 & & \\
\hline 1848 & & & & 3 & 3 & 3 \\
\hline 1849 & & & & 6 & 2 & 4 \\
\hline 1850 & & & & 7 & 6 & 4 \\
\hline 1851 & & & & 3 & 6 & \\
\hline 1852 & & & & 3 & 2 & 2 \\
\hline 1853 & & & & 1 & 1 & \\
\hline
\end{tabular}


El cuadro precedente refuerza nuestra aseveración inicial cuando señalamos que la Universidad era pequeña y que los doctores en leyes eran escasos: 31 en total en todo el período. Sin embargo, la vieja casa de altos estudios a pesar de su pobreza era respetada y siguió cultivando las nuevas generaciones bajo la sombra de sus claustros y formando a aquellos hombres, fuesen clérigos o seglares, que supieron acceder a los distintos espacios de poder desde donde colaboraron a trazar los distintos proyectos políticos emprendidos entre 1820 y 1853 , año éste de la sanción de la constitución nacional.

\section{El Congreso de 1824 y los Universitarios}

Si bien es cierto que el año 1820 marca el derrumbe del poder nacional, a lo largo de esa década hubo varios intentos de reorganizar el país. ¿Quiénes fueron los que se destacaron en esta etapa conflictiva para la Nación? ¿Qué tipo de participación tuvieron? ¿La enseñanza de la Casa de Trejo estuvo presente en sus aportes? ¿Las redes sociales entramadas en las épocas de estudiantes tuvieron que ver en las lealtades políticas que mantuvieron luego?

Para responder estas preguntas es preciso advertir en primer lugar que la situación política del período fue conflictiva y que los egresados de esta Universidad representaron no sólo a Córdoba sino también a otras jurisdicciones provinciales. En segundo lugar, cabe señalar que ante la ausencia de un gobierno central las provincias -en manos de caudillos- se relacionaron desde entonces y hasta la sanción de la constitución nacional en 1853 a través de Pactos, Reglamentos y Estatutos con los que se procuró delinear los poderes del Estado, su forma de integración, elección, atribuciones, así como el conjunto de derechos y deberes que le incumbían al ciudadano. $\mathrm{Y}$ en esa tarea los universitarios tuvieron una destacada actuación.

Si bien eran épocas difíciles cabe subrayar que, a mediados de la década de 1820, hubo un nuevo intento de reunir a las provincias en un Congreso General Constituyente, esta vez en Buenos Aires, con la idea de sancionar una constitución nacional. Desde el inicio de las discusiones, las provincias manifestaron sus ideas respecto a la forma de gobierno a adoptar. Córdoba, Mendoza, San Juan y Santiago del Estero se pronunciaron por un gobierno republicano, representativo y federal. Salta Tucumán y La Rioja por el régimen representativo republicano de unidad. Catamarca, San Luís y Corrientes comprometieron su opinión por el voto del Congreso. Obviamente Buenos Aires presionó para que se adoptara una forma de gobierno representativa republicana y consolidada en la unidad de régimen, lo que fue rechazado por las provincias. 
Pero lo interesante de enfatizar de estas deliberaciones fue la postura que sostuvieron algunos ex universitarios. Por ejemplo, José I. Gorriti señaló que de ningún modo deseaba ser gobernado por los porteños, mientras el Dr. Manuel Antonio Castro, en esta oportunidad convencional por la provincia de Buenos Aires, tuvo una participación significativa pues además de ser el primer presidente del Congreso y redactor del manifiesto que acompañó a la constitución intervino activamente para definir a la Nación y la nacionalidad. En realidad, ambos términos fueron reconocidos por la Convención Constituyente aunque el Congreso no se abocara directamente a esa cuestión. Pero a raíz de la guerra con el Brasil y ante la necesidad de organizar un ejército nacional el tema salió a la luz. En esa oportunidad, Castro lo expuso de la siguiente manera:

...deseo absolutamente que se fije una verdad, que se ha puesto en duda a pesar de ser cierta: que es la existencia de la nación, porque desde el momento que no hay nación. Nada hay. Para ello pido que se lea la (sic) acta original de la independencia celebrada en el anterior Congreso General Constituyente a nombre de todas las provincias juntas. ${ }^{24}$

Y dirigiéndose a los diputados Paso, Acevedo y Bulnes que habían sido congresales en Tucumán en 1816 les solicitó que manifestaran cuál había sido la intención de las provincias que entonces representaban de constituir una Nación libre:

¿Si fue realmente el constituir por aquel pacto una nación libre? Que se me diga si ¿hay algún pueblo que se haya retraído de este pacto o si hay un solo hombre en las provincias que sienta lo contrario?... Pero a más de haber mandado todas las provincias a este mismo efecto sus diputados a Buenos Aires, estando ellos reunidos en Congreso, éste a nombre de todas ellas y al mismo modo que el anterior Congreso lo hizo, se invistió el carácter de una nación libre, ratificando aquel pacto del modo más solemne”. Hay pues nación clamó Castro Barros y añadió

"Hay nación, pues señor diputado: no hay gobierno constituido, pero nación hay y nación que de hecho ya ha pronunciado sus leyes. La nación precede a la constitución, pues aunque como he dicho, no será nación enteramente constituida, es nación que formará su constitución".

A lo que Castro Barros se pregunta “¿mientras no se dé esta constitución,

\footnotetext{
24 SEGHESSO DE LÓPEZ, María Cristina. (2000):“El pensamiento político en el Congreso Constituyente de 1824-1827”, en Historia y evolución de las ideas políticas y filosóficas argentinas, Academia Nacional de Derecho y Ciencias Sociales de Córdoba, Córdoba, pp. 67 y ss.
} 
esta Nación unida por un pacto, que ya ha reproducido, habrá de dejar su suerte expuesta a la aventura, sin tener una fuerza como todas las naciones? ${ }^{25}$

Amigo aunque no compañero de estudios- de Manuel Antonio de Castro fue Dalmacio Vélez Sársfield, ${ }^{26}$ quien cursó sus estudios en Córdoba de acuerdo al plan de estudio del Deán Funes. En esta ocasión representó a la provincia de San Luis a raíz que gobernaba en esa provincia su cuñado, lo que confirma que los universitarios cordobeses estuvieron presentes en los distintos proyectos políticos del país no siempre representando a Córdoba. En esa oportunidad, actuó además como secretario durante las sesiones preparatoria. Su compañero de aulas fue Elías Bedoya y él también formó parte del Congreso Constituyente de 1824. ${ }^{27}$ Ambos emigraron en la época de Rosas, sólo que este último regresó recién después de Caseros para ocupar cargos en el gobierno de Urquiza. ${ }^{28}$

\footnotetext{
${ }^{25}$ ASAMBLEAS CONSTITUYENTES ARGENTINAS, Tomo I, sesión, 4-V-1825.

${ }^{26}$ Vélez estuvo en el Colegio Monserrat y recibió su diploma de bachiller en leyes en la Universidad de Córdoba donde cursó sus estudios según el plan del Deán Funes implementado en 1815. LEVAGGI, Abelardo. (2005): Dalmacio Vélez Sársfield jurisconsulto, Universidad Nacional de Córdoba, Facultad de Derecho y Ciencias Sociales, p. 45; A. TORRES, Félix. (1997): Dalmacio Vélez Sársfield en la Universidad y su correspondencia en Córdoba, Córdoba.

${ }^{27}$ Elías Bedoya nació en Córdoba en 1800, cursó sus estudios en la Universidad donde recibe en 1820 el título de Dr. En derecho civil y canónico. Fue electo diputado por Córdoba en el Congreso de 1824 donde demostró ser partidario del sistema unitario de gobierno. En 1829 acompañó al general Paz en su campaña por el interior y años después a Lavalle quien le confió una comisión en Jujuy, ese año 1841 terminó huyendo a Bolivia y luego pasó a Chile. A la caída de Rosas regresó al país y ocupó el cargo de visitador de aduanas nacionales y más tarde fue ministro de hacienda. Se retiró de la función pública en 1860, falleciendo en Córdoba en octubre de 1870

${ }^{28}$ Heinicio y Vinnio iniciaron a Vélez en el derecho romano, ciencia que al igual que el derecho canónico cultivó durante toda su vida. Católico liberal defendió los derechos de la Iglesia al punto de escribir que "no hay en el país un interés que sea más grande, más general que el interés religioso". Tuvo en la ciudad mediterránea escasa actuación, desempeñándose sólo como defensor de pobres. Desembarcó en Buenos Aires en momento de la convocatoria del Congreso de Rivadavia y a partir de allí su accionar futuro estara unido a esa ciudad donde pasó la mayor parte de su vida. Fracasada la invasión unitaria de Juan Lavalle a Buenos Aires en 1840 y al recrudecer la persecución contra los opositores de Rosas se exilió en Montevideo dos años después. A la caída de Rosas volvió con toda intensidad a la actividad política y defendió los intereses de Buenos Aires ante la Confederación. Fue senador, convencional, reorganizador del Banco de la Provincia, asesor del gobierno, ministro de Relaciones Exteriores y del Interior de Sarmiento. Su obra es vasta pero, sin duda, por su relevante importancia destacamos la redacción del Código Civil argentino en 1863 y aprobado por Ley No 340 del 29 de Septiembre 1869. Contó para esta tarea con la colaboración de Eduardo Acevedo y el joven estudiante Victorino de la Plaza. El mismo entró en vigor el $1^{\circ}$ de Enero de 1871 reemplazando las "Leyes de Indias", que se aplicaban supletoriamente desde la Revolución de Mayo.
} 


\section{El papel de los Universitarios de la "Generación del 37"}

Desde mediados de los años treinta el país siente el peso de las épocas de la anarquía y el despotismo. En Córdoba, Manuel López está al frente del ejecutivo entre 1835 y 1852, gobierno que coincide ideológicamente y en el tiempo con el de Juan Manuel de Rosas en Buenos Aires.

Varios universitarios cordobeses participaron de esta etapa y en la siguiente, destacándose entre ellos Juan del Campillo, José Ramón Ferreira, Santiago Derqui, Agustín Pastor de la Vega, Enrique Rodríguez, José Ramírez de Arellano, Agustín San Millán, Jerónimo Yofré, José Clemente Villada y José Roque Funes, que fue gobernador en 1831. Algunos participaron del gobierno de Manuel López como funcionarios ejerciendo como defensores de pobres, jueces de paz, alcaldes, comisario de abastos públicos, electores y representantes, etc. ${ }^{29}$ Muchos otros por su clara posición política contra el gobierno de Juan Manuel de Rosas que quería perpetuarse en el poder e impedía la organización nacional sufrieron el ostracismo ora en Montevideo, Bolivia o Chile desde donde lanzaron sus escritos con singulares matices.

Pertenecían estos jóvenes al movimiento romántico o lo que se conoce como la generación de 1837. El bagaje intelectual que ellos tenían era ecléctico y provenía de distintas vertientes de la cultura europea, en especial de Francia: Saint Simón, Lamennais, el asociacionismo de Considerat, los escritos de Benjamín Constant y el nacionalismo republicano de Mazzini a través de la Joven Italia fueron los referentes más nombrados. Tenían en claro la necesidad de fortalecer la educación y la inmigración para lograr el crecimiento del país extenso y deshabitado. En materia religiosa se pronunciaron por la libertad de cultos. Este caudal de conocimientos les posibilitó construir un pensamiento ecléctico, aunque sin dudas debemos señalar que todos soñaban con un país mejor y con la sanción de una constitución. Muchos mantuvieron contacto con la Universidad. A raíz de la creación de la Cátedra de Derecho Público por decreto del gobernador de Córdoba, José Antonio Reynafé el 28 de febrero de 1834 se planteó la nueva distribución de materias disminuyendo el estudio de los derechos Civil y Canónico e incorporando en el cuarto año el Derecho Público, cátedra que contó entre sus primeros docentes a los doctores Santiago Derqui,

${ }^{29}$ FERREYRA, Ana Inés. (1992): Elite Dirigente y vida cotidiana en Córdoba, 1835-

1852, Centro de Estudios Históricos, p 107. 
Agustín Pastor de la Vega, Enrique Rodríguez y Ramón Ferreyra. ${ }^{30} \mathrm{La}$ cátedra perduró hasta el 3 de marzo de 1841, cuando a pedido del claustro universitario fue suprimida por decreto del gobernador delegado Claudio Antonio Arredondo. Los nuevos saberes influyeron en el grupo universitario quien reaccionó políticamente en contra del poder político de Rosas. Es que las ideas de Estado y Nación están presentes en el discurso de estos jóvenes románticos que exhiben una disposición política. Así es como el núcleo antirrosista une al campo de las ideas el recurso de las armas.

Un acontecimiento ocurrido en Buenos Aires precipitó al grupo lanzarse contra el gobernador de Córdoba. En efecto, en 1839 se levantó en esta última ciudad una conspiración contra Juan Manuel de Rosas, entre los participantes se encontraba el joven coronel Ramón Maza. El complot es descubierto y Maza

${ }^{30}$ Derqui llegó a ser presidente de la Confederación Argentina (1860-1861). Nacido y educado en Córdoba recibió su doctorado en derecho en 1831. Fue profesor de filosofía y vicerrector de la Universidad. Miembro de la legislatura provincial; colaboró para salvar al general Paz de su ejecución, después de su captura en El Tío, estableciendo un estrecho vinculo con aquél. Como opositor a Rosas, editó El Cordobés. Se exilió en Santa Fe y más tarde en Uruguay; cooperó con Lavalle y con otros adversarios de Rosas; fue enviado por Rivera en 1840 para negociar con Pedro Ferré, gobernador de Corrientes. Se unió a Paz en carácter de secretario y brevemente, como su ministro en Entre Ríos en 1842; posteriormente, alternó el exilio con el retorno a la lucha, especialmente en Corrientes. Después de Caseros, fue electo por Córdoba como delegado para el congreso Constituyente en Santa Fé (1853); fue electo vicepresidente y luego presidente de dicho congreso. Prestó servicios como ministro de Justicia, Culto e Instrucción Pública y posteriormente como ministro del interior; sucedió a Urquiza en la presidencia de la Nación en 1860; tuvo una activa participación en las negociaciones conducentes a reunificar a la provincia de Buenos Aires con la Confederación. El panorama parecía favorable pero se desarrollaron complicaciones debido a varias causas: Derqui debió afrontar problemas políticos internos, al igual que Bartolomé Mitre, quien en aquel momento había sido designado gobernador de Buenos Aires; se suscitaron fricciones personales entre Derqui, que tenía sus propias ideas sobre el gobierno, y Urquiza, ahora gobernador de Entre Ríos pero también comandante en jefe de las fuerzas armadas, quien estaba determinado a que no se echara por tierra sus esfuerzos directos a plasmar la Confederación; ambos entablaron negociaciones personales con Mitre. La intervención de San Juan por parte de Derqui y la consiguiente revuelta originada en el lugar intensificaron el malestar. El 9 de julio de 1860 se reunió con el general Urquiza y el gobernador Mitre en Buenos Aires para la celebración del aniversario de la Independencia, pero la paz que esto simbolizaba se vio rápidamente deteriorada por el inicio de hostilidades. El 17 de septiembre de 1861, Mitre enfrentó a Urquiza, en Pavón donde este lo derrotó, pero el flanco central mitrista embistió al de la Confederación. Ninguno de ambos bandos se había aún alzado con la victoria, a pesar de que gran parte de la artillería de la Confederación había sido capturada, cuando Urquiza, quien de todas formas no tenía esperanza alguna en la victoria, se replegó. La continua acción militar y demostración de fuerza por parte de Mitre, así como también sus negociaciones con los gobernadores de las provincias mesopotámicas y su habilidad política contribuyeron a la reunificación de la Nación, de la cual se convirtió en presidente en 1862. Derqui, sin apoyo alguno después de Pavón, renunció a su cargo presidencial en noviembre de 1861, marchándose al exilio; más tarde regresó a Corrientes, donde murió en 1867. 
y su padre, Manuel Vicente Maza, que era presidente de la legislatura porteña, fueron asesinados.

El suceso sembró el terror en la sociedad porteña, sobraban los sospechosos y como escribió José María Paz en sus Memorias "los semblantes no indicaban sino duelo y malestar". La conjura había sido sofocada pero no destruida y como consecuencia de la postura adoptada muchos jóvenes pertenecientes a la generación del 37 sufrieron serias consecuencias: fueron apresados, mientras, otros, buscaron rápidamente refugio en Montevideo o Chile. De este momento haremos referencia a la persona de Vicente Fidel López, un joven de escasos 25 años, hijo del autor del himno nacional que comprometido con las ideas del grupo contrario a Rosas advirtió a su padre que debía alejarse un tiempo de Buenos Aires. Éste le aconsejó que se estableciera en Córdoba, donde no sólo contaba con familias conocidas sino que la ciudad podía ser un incentivo para su vida social e intelectual. No fue así, pues las cuestiones políticas se complicaron y la victoria de Oribe sobre Lavalle en la batalla de Quebracho Herrado en noviembre de 1840 hizo posible que, Rosas, permaneciera doce años más en el poder. Chile sería entonces el destino final que le esperaba a Vicente F. López.

De todos modos, lo que nos interesa destacar es que cuando llegó a Córdoba en marzo de 1840 se instaló en la casa de la familia Lozano, uno de cuyos miembros - Cayetano- había sido diputado en 1837. En el corto tiempo de su permanencia en la ciudad se preocupó por conspirar contra Rosas y por hacer conocer el pensamiento revolucionario del grupo al que pertenecía fundando junto a otras figuras del ambiente político cordobés una filial de la Asociación La Joven Argentina, una entidad inspirada en el accionar desplegado por Giuseppe Manzini en La Joven Italia. Entre sus prosélitos se encontraban entre otros Francisco Álvarez, Ramón Ferreira, Enrique Rodríguez, Paulino Díaz, José Norberto de Allende, ${ }^{31}$ Mariano y Francisco González, Dionisio Rizzo Patrón, varios de ellos abogados, condiscípulos o docentes de la Universidad que actuaron en diferentes ocasiones de la vida pública y algunos comerciantes de fortuna como Cayetano y Francisco Lozano y Gaspar Bravo, cuyos bienes fueron confiscados por su participación en este conflicto.

A los pocos meses de su llegada Vicente F. López logró editar en la imprenta de la Universidad un periódico titulado El Estandarte Nacional, cuyo primer número vio la luz el 24 de octubre de 1840 y el último el 2 de diciembre del

\footnotetext{
31 Allende, fue un personaje que actuó en Córdoba desde muy temprano. Fue varias veces miembro del cabildo, participó de las gestiones de José Javier Díaz, de J. B. Bustos y del general José María Paz; fue uno de los redactores del Reglamento Provisorio de Córdoba de 1821 .
} 
mismo año. El lema del mismo, como no podía ser de otra manera era "Libertad, Constitución o Muerte", aunque se planteaba que sus páginas tenían el fin de tratar temas políticos, literarios y mercantiles. No obstante, de la lectura de los doce números editados, se desprende que en los artículos y en los párrafos escritos por Vicente Fidel tienen como meta ir contra la figura de Juan Manuel de Rosas y su tiranía ${ }^{32}$ a quien adjudica "aniquilar" a la gente industriosa y a la juventud ilustrada.

En sus relatos el joven escritor cantó loas al movimiento revolucionario ocurrido el 10 de octubre de 1840, momento que ingresó a la provincia de Córdoba el general Lamadrid con su fuerza levantando el lema de "Libertad y Constitución". Pareció por un momento que el sueño de libertad pregonado por los universitarios se cumplía. Ante esta situación José Francisco Álvarez, joven abogado, que presidía la filial de cordobesa de la Joven Argentina fue designado gobernador de la provincia. Su primer acto de gobierno fue retirar a Rosas las facultades que le habían conferido para mantener las Relaciones Exteriores de la República. Eran momentos de euforia para los jóvenes revolucionarios.

Lamentablemente, la batalla de Quebracho Herrado tiró por tierras dichas ilusiones. La noticia de la derrota llegó velozmente a Córdoba, en consecuencia el gobernador Manuel López recuperó su cargo y muchos de los férreos opositores al régimen rosista que habían participado del gobierno de Álvarez como Marcial y Cupertino Ocampo, Igarzábal, Posse, Soage y Miguel Piñero se encaminaron a Chile. ${ }^{33}$ Más tarde, algunos con espíritu más aventurero se largaron hasta California cuando se desató allí la fiebre del oro.

En realidad muchos de los jóvenes que Rosas persiguió se desparramaron por todas partes, unos viajaron a Europa, otros a Chile o Uruguay estudiando derecho y formas de gobierno y a su regreso trajeron "un tesoro inmenso de conocimientos, de experiencias, datos preciosos que pondrán un día, al servicio de la patria". Entonces "la inteligencia, el talento y el saber serán llamados de nuevo a dirigir los destinos públicos, como en todos los países civilizados." ${ }^{\text {34 }}$

${ }^{32}$ GHIRARDI, Olsen. (2005): Vicente Fidel López en Córdoba, Córdoba, Edit. Advocatus. ${ }_{33}$ ARCHIVO HISTORICO DE LA PROVINCIA DE CORDOBA [en adelante AHPC], Crimen, 1842, Capital, Leg. 198, Ex. 13. Clasificando de unitarios y expulsando por la conducta política que guardaron en el motín del 10 de octubre de 1840. Juan José Espinosa, deán de la catedral, José Gregorio Patiño, Canónigo honorario Estanislao Learte, Miguel Calixto del Corro, José Gregorio Carranza, Manuel Eduardo Álvarez, Maestro Francisco Javier... Sacerdote. AHPC, Crimen, 1843, legajo 200 Exp. 4 Habladurías subversivos del orden público. IDEM, Crimen 1845, Capital, legajo 208, Exp.8.

${ }^{34}$ SARMIENTO, Domingo Faustino. (1971): Facundo, Buenos Aires, Kapeluz, p. 321. 
Efectivamente así fue y en la sanción de la constitución nacional y en las cartas provinciales ellos dijeron presente.

\section{Los Universitarios a la Caída de Rosas}

Al caer la tiranía de Juan Manuel de Rosas paulatinamente fueron cayendo los gobernadores acólitos y se inicia el período que se conoce como de Organización Nacional. En Córdoba el gobernador Manuel López fue destituido el 27 de abril de 1852 y en su lugar asumió Alejo Carmen Guzmán, hombre de la universidad y católico acérrimo.

En este período, las ideas políticas debían plasmarse en un proyecto superador. La antinomia de unitarios y federales y la lucha de Buenos Aires y su poderosa Aduana, en detrimento del resto del país o vulgarmente de Urquiza y sus "trece ranchos", como despectivamente designaban los porteños al resto de las provincias debía resolverse.

La sanción de la Constitución Nacional de 1853, sus reformas de 1860 y 1866 y la redacción de las constituciones provinciales contaron, otra vez, con el auxilio de varios universitarios cordobeses, particularmente de los abogados quienes se abocaron en ese período fundacional a la formulación de las leyes que reglamentaron su ejercicio y a la puesta en funcionamiento de los Poderes Ejecutivo; Legislativo y Judicial como así también de otras instituciones que regulaban la relación entre los ciudadanos y el Estado y los particulares entre sí y que sería largo enumerar. De esta etapa sobresalen las figuras de Santiago Derqui, Sarachaga, Mariano Fragueiro, Elías Bedoya, José Severo de Olmos, Donaciano del Campillo, Nicolás Avellaneda, Manuel Lucero, Gerónimo Cortés, La mayoría no eran hombres improvisados; descendían de familias españolas, católicas, fueron formados en la Universidad o en seminarios eclesiásticos, es decir contaban con una educación adecuada para las funciones públicas.

Los hombres de esta etapa no se olvidaron de la Universidad y se comprometieron a mejorar la enseñanza superior. Por eso una de las medidas que dicta el gobierno de la Confederación fue nacionalizarla. Los efectos de esta medida no tardaron en visualizarse: se reformó el edificio, se aumentaron las dotaciones de cátedra y se redactó una constitución provisoria que reglamentó las funciones administrativas. Además de otorgar becas para que estudiantes de las distintas provincias pudieran educarse viviendo en el Colegio Monserrat, ${ }^{35}$ pero esa es otra historia.

35 VERA DE FLACHS, María Cristina. (1999): Finanzas, saberes y vida cotidiana en

el Colegio Monserrat. Del Antiguo al Nuevo Régimen, Córdoba. 


\section{CONCLUSIONES}

Al inicio del artículo nos planteamos averiguar cuáles fueron los universitarios que desde temprano participaron en el proceso de formación de la Nación y que tenían en común. Los que participaron de los proyectos políticos de la primera época independiente eran hijos de la Ilustración Católica, algunos ex alumnos de los jesuitas. Las ideas políticas de los hombres que pasaron por las aulas de la Casa de Trejo se basaron en "las doctrinas suaristas y tomistas las que ejercieron influencia profunda y cultivaron, antes de la revolución, la doctrina de la soberanía popular, preparando una legión de hombres que entraron en ella como mentores escuchados, ejercitando una autoridad indiscutible, clarovidente y moderadora" 36

Al expirar el orden colonial, Gregorio Funes, J. I. Gorriti, Castro Barros y muchos otros universitarios estuvieron dispuestos a actuar activamente en la política local y nacional. Por lo general mostraron cierta prevención hacia la ciudad de Buenos Aires, el puerto y sus habitantes. Eran hombres instruidos y con conocimiento de las ideas que circulaban en Europa. Esa preparación les posibilitó formar parte de los distintos intentos de organización del Estado. Los congresistas que representaron a las distintas provincias en el Congreso de Tucumán coincidieron en su mayoría con los conceptos expresados por los triunviros de Córdoba y encabezaron en esa instancia la resistencia federal de las provincias del interior contra el puerto.

Lamentablemente las diatribas y peleas de los caudillos les restaron fuerzas a esos universitarios para solucionar los problemas organizacionales del país. No obstante, tenemos que reconocer que los Estatutos, Reglamentos provisorios $\mathrm{y}$ constituciones que fueron apareciendo a partir de 1819 contaron con su aporte. Los universitarios que participaron de la etapa que coincide con el período rosista -pertenecían al movimiento romántico, a la generación de 1837. La cuna de la cultura era Europa, en especial Francia. Sus influencias provenían de distintas vertientes: Saint Simón, Lamennais, el nacionalismo republicano de Mazzini a través de la Joven Italia, el asociacionismo de Considerat, lo que les posibilitó construir un pensamiento ecléctico. En materia religiosa se pronunciaron por la libertad de cultos, pero se reconocieron católicos. Soñaban con un país mejor y con la sanción de una constitución.

En su vida activa mantuvieron contacto con la Universidad. Pertenecían a la élite dirigente provincial y nacional y entre ellos tenían relaciones de

\footnotetext{
${ }^{36}$ MARTINEZ VILLADA, Luis G. (1919): "Notas sobre la cultura cordobesa en la época colonial" en Revista de la Universidad de Córdoba, año VI, No 9-10, Córdoba, p. 24.
} 
parentescos o amistad, los que fueron utilizados en su accionar político. En su mayoría se declararon federales, teniendo en cuenta que este término era en la época una actitud de gobierno. Muchos sufrieron el ostracismo, ora en Montevideo, Bolivia o Chile, desde donde lanzaron sus escritos con singulares matices. Al regresar muchos pusieron en marcha sus proyectos gestados en el exilio los que dieron fruto hacia 1880 .

Por último interesa destacar que más allá de las coincidencias políticas o ideológicas de los miembros del grupo analizado formaron parte de la elite política de la Nación y en su conjunto, se identificaron siempre con la Universidad de Córdoba.

\section{FUENTES}

RAVIGNANI, Emilio. (Compilador). (1937). Asambleas Constituyentes Argentinas. Buenos Aires.

ARCHIVO GENERAL DE LA UNIVERSIDAD DE CORDOBA- A.G.U.C., Libro 7, Documentos. 1823-1826, fs. 96 a 151 y 257 a 259.

AHPC, Crimen, 1842, Capital, Leg. 198, Ex. 13. 1843, legajo 200 Exp. 4 Habladurías subversivos del orden público. Crimen 1845, Capital, legajo 208, Exp.8.

INSTITUTO DE ESTUDIOS AMERICANISTAS- I.E.A., Documento No 12.791.

Escritos políticos del deán Gregorio Funes. 1810-1811" en Estudios $\mathrm{N}^{\circ}$ 11-12, diciembre de 1899, Universidad Nacional de Córdoba, CEA.

\section{REFERENCIAS}

AYROLO, Valentina. (2007): Funcionarios de Dios y de la república. Clero y politica en la experiencia de las autonomías provinciales, Buenos Aires, Editorial Biblos.

AYROLO, Valentina. (2003): Una Iglesia del interior de las Provincias Unidas: Córdoba en la primera mitad del siglo XIX, Jahrbuch für Geschichte Lateinamerikas 40, Böhlau Verlag Köln/Weimar/Wien.

BERTRAND, Michel. (2000): "Los modos relacionales de las elites hispanoamericanas coloniales: enfoques y posturas", en Anuario del IEHS, $\mathrm{N}^{\circ} 15$, Tandil.

CABRERA, Pablo. (1930): La segunda imprenta de la Universidad de Córdoba, Córdoba, Universidad Nacional de Córdoba.

FERREYRA, Ana Inés. (1992): Elite Dirigente y vida cotidiana en Córdoba, 18351852, Córdoba, Centro de Estudios Históricos.

FUNES, Gregorio. (1970): Borrador del original de la oración fúnebre por las exequias 
de Carlos III pronunció en esta ciudad de Córdoba el Deán Don Gregorio Funes, año 1790, Imprenta de Niños Expósitos, Colección Pablo Cabrera.

GHIRARDI Olsen. (2005): Vicente Fidel López en Córdoba, Córdoba, Edit. Advocatus.

GUERRA, Francois Xavier. (2000): "El análisis de los grupos sociales: balance historiográfico y debate crítico" en Anuario IEHS, $\mathrm{N}^{\circ} 15$, Tandil.

INGENIEROS, José y BORREDA LYNCH, Julio. (1937): La evolución de las ideas argentinas, Buenos Aires, Talleres J. Rosso, Talleres gráficos argentinos.

LEVAGGI, Abelardo. (2005): Dalmacio Vélez Sársfield jurisconsulto, Universidad Nacional de Córdoba, Facultad de Derecho y Ciencias Sociales.

LIQUENO, José M. Fr. (1917): Influencia de la Universidad de Córdoba en la revolución de la independencia argentina, Composición que obtuvo el primer premio en el Certamen "Centenario Nacional" de 1910, celebrado en Córdoba, Córdoba, Imprenta Cubas.

LIQUENO, José M. Fr. (1916): El catolicismo y sus adversarios en Córdoba, Córdoba, Rip. Vita Coloniale, 1916. Conferencia dada en el Colegio Santo Tomás el 30 de septiembre de 1916.

LOBO, Héctor Ramón. (2010): Historia de Córdoba, Tomo III: Ocaso y despertar, Córdoba, Ediciones Del Copista.

LOZANO, Mariano. (1910): Biografia del Dr. Gregorio Funes, autor del Ensayo de Historia Civil del Paraguay, Buenos Aires, Talleres J. Rosso y Cía.

LOZADA ECHENIQUE, Juan Carlos. (1960): "Las ideas y tendencias de la revolución de mayo" en Revista de la Junta Provincial de Historia de Córdoba, $\mathrm{N}^{\mathrm{0}} 1$.

PEÑA, Roberto. (1992): "Los derechos naturales del hombre en la ideología del siglo XVIII Rioplatense", en Academia Nacional de Derechoy Ciencias Sociales de Córdoba, Instituto del Derecho y de las Ideas Políticas, Cuadernos de Historia $N^{o} 2$.

PEÑA, Roberto. (1998): "El Doctor Manuel A. de Castro: gobernador de Córdoba, 18171820", en Cuadernos de Historia, Academia Nacional de Derecho y Ciencias Sociales, Córdoba.

MARTINEZ VILLADA, Luis G. (1919): "Notas sobre la cultura cordobesa en la época colonial" en Revista de la Universidad de Córdoba, año VI, N 9-10, Córdoba.

MOLINA, Eugenia. (2001): "las modernas prácticas asociativas como ámbitos de definición de lazos y objetivos políticos durante el proceso revolucionario (18101820)" en UNIVERSUM, $N \quad{ }^{\circ} 16$, Talca.

MOLINA, José. (1888): "El doctor don Pedro Ignacio de Castro Barros", en Revista Nacional, Tomo VII, Buenos Aires.

MOLINA GONZÁLEZ, José Luís. (2005): "El estudio de las redes personales", en EMPIRIA, en Revista de Metodología de las Ciencias Sociales, $n^{\circ} 10$, juliodiciembre.

Rhela. Vol. 14. Año 2009, pp. $191-218$ 
SARMIENTO, Domingo Faustino. (1971): Facundo, Buenos Aires, Kapeluz.

SEGHESSO DE LÓPEZ María Cristina, "El pensamiento político en el Congreso Constituyente de 1824-1827", en Historia y evolución de las ideas políticas y filosóficas argentinas, Academia Nacional de Derecho y Ciencias Sociales de Córdoba, Córdoba, 2000.

SILLAU PEREZ, Antonio. (2001): “Contenido y características del pensamiento político de Ignacio de Castro Barros en la primera década revolucionaria" en Revista de la Junta Provincial de Historia, $\mathrm{N}^{\circ} 18$, Córdoba.

TONDA, Américo. (1961): Castro Barros. Sus ideas, Academia del Plata, Buenos Aires.

TORRES, Félix A. (1997): Dalmacio Vélez Sársfield en la Universidad y su correspondencia en Córdoba, Córdoba.

VERA DE FLACHS, María Cristina. (1999): Finanzas, saberes y vida cotidiana en el Colegio Monserrat. Del Antiguo al Nuevo Régimen, Córdoba.

VERA DE FLACHS, María Cristina. (1999): “Gregorio Funes: un criollo ilustrado y la reforma del plan de estudios de la Universidad de Córdoba", en Científicos Criollos e Ilustración, Editorial Doce Calles, Madrid.

VERA DE FLACHS, María Cristina. (1987): "La Universidad como factor de ascenso a la elite de poder de la América Hispana: el caso de Córdoba”, en Congreso Internacional de Historia de las Universidades Americanas y Españolas, Claustros y Estudiantes. Facultad de Derecho, Universidad de Valencia, España.

VERA DE FLACHS, María Cristina; FERRERO MICO Remedios, (1996): Finanzas y poder político en las Universidades Hispanoamericanas. El caso de Córdoba 1613-1854. Córdoba, El Copista.

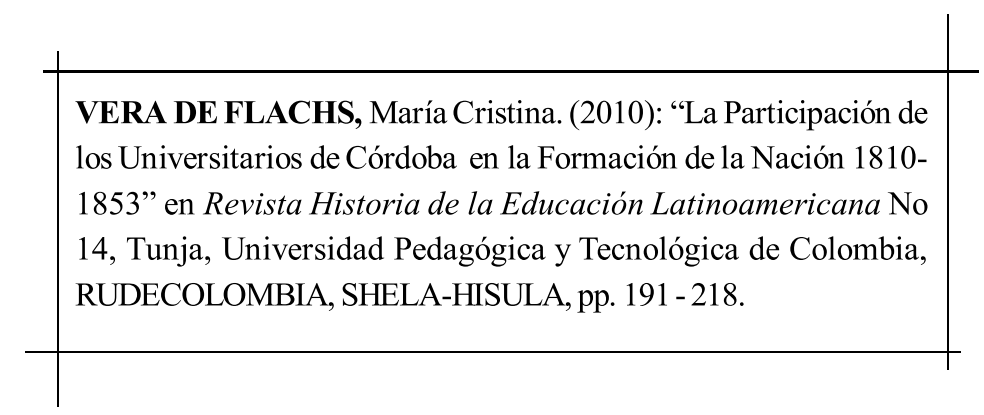

Rhela. Vol. 14. Año 2009, pp. $191-218$ 